\author{
IRENA CHAWRILSKA \\ (D) https://orcid.org/0000-0001-7699-6551 \\ Uniwersytet Gdański \\ Gdańsk
}

\title{
Transmedialność jako transkulturowe doświadczenie ucznia
}

Transmediality as a transcultural experience of students

\begin{abstract}
Designing classes with the contribution of students who experienced migration and those without similar experiences becomes a didactic, pedagogical and cultural challenge. The aim of this paper is to analyse such phenomena in culture, which may provide inspiration for teachers as to how to think about teaching Polish culture in primary and secondary schools. The field for investigation is defined by the categories of transmediality and transculturality, since in the author's opinion the constant experiencing of transmediality and transmedia storytelling in culture results in transcultural experiences. The author's deliberations are based on examples from experimental poetry, forum theatre and ambient literature.
\end{abstract}

Key words: transmediality, transculturality, interculturality, students with migration experience

Tout homme est un artiste. Joseph Beuys

Architektura mózgu, zasadniczo tożsama dla wszystkich homo sapiens, stanowi podstawę transkulturowego odbioru dzieł sztuki.

Wolfgang Welsch

W polskiej rzeczywistości szkolnej uczeń z doświadczeniem migracyjnym jest uznawany za ucznia o specjalnych potrzebach edukacyjnych (Gębal 2018)1. Polska szkoła stanęła przed wyzwaniem zapewnienia wsparcia ucz-

1 Zagadnienie to podejmuje Przemysław Gębal w książce Podstany dydaktyki jezykea polskiego jako drugiego. Podejście integracyjno-inklusyjne. Współcześnie na gruncie polskim mówimy o glot- 
niom z doświadczeniem migracji nie tylko w ramach edukacji włączającej, lecz także w nauce języka polskiego jako drugiego i kultury polskiej (Lipińska, Seretny 2018, 92)2. Istotne jest nauczanie języka polskiego jako narzędzia umożliwiającego komunikację, poznawanie świata i nawiązywanie w nim relacji. W sytuacji szkolnej ważne jest też przygotowanie ucznia do skutecznego wykorzystywania tekstów specjalistycznych, nauki języka w taki sposób, żeby był on w stanie przyswajać wiedzę i konstruować wypowiedzi w języku specjalistycznym ${ }^{3}$. Na szkolnych lekcjach polskiego uczniowi niezbędny jest język nauki o literaturze, nauki o języku i wiedzy o kulturze, żeby skutecznie przygotować się do egzaminu maturalnego, który nadal sprawdza opanowanie zagadnień z podstawy programowej z 2012 roku$^{4}$. Zakładane wyniki sa bardzo trudne do osiagnięcia przez nierodzimych użytkowników języka. Biorąc pod uwagę opisany w glottodydaktyce dwuletni czas potrzebny do tego, by uczniowie opanowali język na poziomie komunikacyjnym i zakładane 5-7 lat, żeby opanować język edukacji szkolnej (Pamuła-Behrens, Szymańska 2018b), proces kształcenia musi zostać zaprojektowany w taki sposób, żeby uczeń z doświadczeniem migracji, który kończy szkołę średnia, miał zrealizowaną podstawę programową z języka polskiego (na poziomie podstawowym).

Projektowanie lekcji z udziałem uczniów z doświadczeniem migracji i tych bez podobnych doświadczeń staje się wyzwaniem dydaktycznym, pedagogicznym i kulturowym. Niniejszy artykuł stawia sobie za cel analizę takich zjawisk w kulturze, które mogą dostarczyć inspiracji nauczycielom, jak myśleć o nauczaniu kultury polskiej w szkole podstawowej i ponadpodstawowej. Polem wyznaczającym zakres rozważań są tu kategorie transmedialności i transkulturowości, ponieważ zdaniem autorki nieustanne doświadczanie transmedialności i narracji transmedialnych w kulturze skutkuje doświadczeniami transkulturowymi.

topedagogice, czyli nauczaniu języków mającym na celu wychowanie interkulturowe do życia w wielojęzycznej i wielokulturowej Europie. Badacz podkreśla, że profesjonalne działania na polu nauczania języka polskiego jako obcego i języka polskiego jako drugiego wymagają współpracy glottodydaktyków polonistycznych oraz pedagogów i psychologów międzykulturowych.

2 Język drugi to nierodzimy język użytkownika i jednocześnie oficjalny/urzędowy kod, posiadający status prawny w miejscu osiedlenia. Jest to również język codziennej komunikacji, a dla młodego pokolenia to język edukacji szkolnej.

3 Tego rodzaju propozycją jest metoda JES-PL (Pamuła-Behrens, Szymańska 2018a).

${ }^{4} \mathrm{~W} 2022$ roku po raz ostatni odbędzie się matura przygotowana zgodnie z wymaganiami podstawy programowej minister Katarzyny Hall, a w 2023 roku po raz pierwszy matura zostanie dostosowana do podstawy programowej przygotowanej przez minister Annę Zalewską. 


\section{Ciało, zmysły, doświadczenie}

Stawiając tezę, że transmedialność staje się doświadczeniem uniwersalnym we współczesnym świecie, należy podkreślić, że w ostatnich latach coraz częściej prowadzone są badania dotyczące uniwersalności bądź przedkulturowości doświadczenia estetycznego. Człowiek ma przedkulturową dyspozycję doświadczania tego, co estetyczne, która nie zostaje unieważniona w procesie wychowania w danej kulturze. Dlatego dzieła artystyczne będące wytworem danej kultury, moga być zrozumiane i uznane za wartościowe w innej kulturze, nawet bez znajomości ich kulturowego kontekstu. Na gruncie psychologii pojęcie 'transkulturowe' oznacza to, co jest w psychice przedkulturowe. Badaniom poddawane są uniwersalne cechy psychiki, które umożliwiają doświadczanie podobnych przeżyć estetycznych przedstawicielom różnych kultur. Celem neuroestetyki natomiast jest wskazywanie neurobiologicznych podstaw doświadczania estetycznego oraz sposobu, w jaki nasz mózg odbiera dzieła artystyczne. Zakłada się, że istnieja takie struktury mózgu, które są wspólne dla wszystkich i umożliwiają doświadczanie estetyczne (Duch 2016).

Badania prowadzone w ramach różnych dyscyplin skłaniają do podobnych wniosków: istnieje wspólna podstawa u homo sapiens, dzięki której jesteśmy w stanie funkcjonować w obcej kulturze nawet bez jej znajomości. Tego rodzaju namysł towarzyszył już Hermannowi Schmitzowi, który rozwijał fenomenologię zakotwiczoną w bezpośrednim doświadczeniu z perspektywy „ja-tu-teraz”, wyprowadzając swój opis rzeczywistości z empirycznych doświadczeń. Nowa fenomenologia, rezygnując z transcendentalizmu i z idei samej świadomości, odkrywała ciało w jego tu-teraz poprzedzającym dychotomię dusza-ciało, pierwotną obecność uczuć i witalne uwarunkowanie człowieka. Schmitz wydobywał i opisywał zjawiska osadzone w pierwotnym doświadczeniu życia - źródłowym oglądzie (Moryń 2008, 6).

Innym językiem swój pogląd wyrażają narratolodzy transmedialni, przekraczający narratologię opisywana językiem strukturalizmu i poststrukturalizmu, a których postawę badawczą określić można ucieleśnionym zwrotem w narratologii (Kaczmarczyk 2018, 52). Polega on na tym, że narracja jako byt mentalny tworzy zróżnicowane kody bazujące na przedjęzykowych doświadczeniach cielesnych, niemające natury symbolicznej. Przejście od paradygmatu „komputacyjnego” czy „koneksjonistycznego” do paradygamtu „ucieleśnionego” odnotowano w całej humanistyce. Zwłaszcza kognitywiści odegrali istotną rolę na tym polu. George Lakoff i Mark Johnson podzielili 
studia kognitywistyczne na pierwszą i druga generację (Lakoff, Johnson 1999, 75-78), której podejście nazwano „4E” od następujących określeń poznania: ucieleśnionego (embodied), umiejscowionego (embeded), rozszerzonego (extended) i ustanowionego (enacted) (Menary 2010, 459-463). Najbardziej radykalni przedstawiciele kognitywistyki uważali, że poznanie można wyjaśnić za pomoca dynamicznych relacji ciała, mózgu i środowiska. Nie ma bowiem konieczności tworzenia reprezentacji świata, kiedy możemy go poznawać w interakcji (Brooks 1990, 5). Mniej radykalni badacze dowodzili, że struktury semantyczne bazują na doświadczeniach cielesnych na takiej samej zasadzie, jak ciało pozostające w nieustającym ciagu interakcji ze światem jest podstawa języka (Lakoff, Johnson 1980). Również we współczesnych badaniach podkreśla się, że doświadczenie cielesne odgrywa bardzo istotną rolę w rozumieniu dyskursu. Za przykład może tu posłużyć Rolf A. Zwaan, twórca modelu Immersed Experiencer Framework, stojący na stanowisku, że odczytywanie słów aktywizuje u odbiorcy struktury neuronalne odpowiadające za doświadczenia z oznaczanym obiektem (Kaczmarczyk 2018, 55). Nie poznajemy narracji za pomocą dekodowania znaków i tworzenie reprezentacji, tylko za pomocą symulacji doświadczenia, należącego do kogoś innego. Odbiorca, przyjmujący perspektywę protagonisty, konstruuje reprezentację świata przedstawionego, jakby w nim uczestniczył.

Ucieleśniony zwrot w humanistyce potwierdza, jak w kulturze zwiększa się zainteresowanie mediami bezpośrednio angażującymi ciało, które nie wymagają od odbiorcy zanurzenia w konkretnej kulturze. Biorąc pod uwage liczne badania z pogranicza filozofii, teorii kultury, kognitywistyki i narratologii, łatwiej uświadomić sobie, o jakich procesach pisał Wolfgang Welsch, kiedy używał kategorii transkulturowości w opozycji do wielokulturowości i interkulturowości (Welsch 1998, 203). W koncepcji Welscha kultury jawią się jako sieci wzajemnych powiązań, poddane nieustannemu procesowi hybrydyzacji, jako pola, na których wciąż dochodzi do negocjacji i transakcji. Posługując się terminami kultura niemiecka czy francuska, mamy na myśli społeczności polityczne i językowe, a nie formacje kulturowe, ale jednocześnie można wskazać cechy takiego tworu, jak kultura japońska czy francuska (Welsch 1998, 203). Transkulturowa, a zatem złożona z wielu przemieszanych elementów, staje się także tożsamość jednostki. Welsch powiada: „Jesteśmy kulturowymi hybrydami" (Wilkoszewska 2004, 42), wskazując jednocześnie, że formowanie się tożsamości dokonuje się dziś nie w obrębie zamkniętej, macierzystej kultury, lecz w procesie mieszania się wielu wpływów, które czasem są już niemożliwe do wyśledzenia. 


\section{Transmedialne opowieści}

Sposób konstruowania opowieści i opowiadania, ulegający nieustannym przemianom, nie jest efektem tylko i wyłącznie zmian technologicznych, lecz wynika z umiejętności wykorzystania możliwości nowych warunków technologicznych i ich przyswojenia przez użytkowników kultury na całym świecie. Transmedialne są te teksty, których narracja prowadzona jest jednocześnie za pośrednictwem różnych mediów ${ }^{5}$. Opowieści znane szerszemu gronu odbiorców funkcjonują we współczesnym świecie dzięki ich transmedialnemu charakterowi. Przepływ treści cyfrowych między różnymi platformami medialnymi jest procesem charakterystycznym dla zjawiska konwergencji w kulturze (Jenkins 2007, 256), w którym dochodzi do nieustających i dynamicznych zmian ról nadawcy i odbiorcy, wszystkie zależności pomiędzy uczestnikami procesów komunikacyjnych, medialnych i komercyjnych są płynne. Dzięki temu treść utworu może zostać przeniesiona na wiele platform medialnych i być stale aktualizowana i nieustannie odczytywana. Najbardziej znanym przykładem opowieści tego rodzaju jest seria Matrix, składająca się z trylogii filmowej, gier komputerowych, filmów anime (Animatrix) i komiksów. Słynna badaczka narracji transmedialnych Marie-Laure Ryan porównuje strukturę świata trylogii Matrix do szwajcarskiego sera, który posiada wiele dziur możliwych do wypełnienia dzięki treściom umieszczonym na innych platformach cyfrowych (Ryan 2015, 7) ${ }^{6}$. Poszczególne fragmenty opowieści wzajemnie od siebie zależa, a treści nie sa powielane na różnych platformach, są względem siebie autonomiczne. Należy jednak zwrócić uwagę na to, że Jenkins w swojej przełomowej książce pisze o poszczególnych mediach, platformach, które zostają zachowane w idealnej formie, każde medium porusza się w sferze, w której jest najlepsze, zachowuje czystość i nie wchodzi w relacje $\mathrm{z}$ innymi mediami. Różne media, wedle Jenkinsa, łączy tylko narracja, ale jeśli dane medium zacznie tworzyć organiczną całość

${ }^{5}$ Samo pojęcie opowieści transmedialnej doczekało się licznych omówień. Termin ten został wprowadzony przez Henry’ego Jenkinsa w książce Kultura konwergencji. Zderzenie starych i nowych mediów, w której definiuje się go jako: „,wielowątkową i zróżnicowaną historię, która odsłaniana jest na różnych platformach medialnych, przy czym każde medium ma swój oddzielny wkład w tworzenie i rozwijanie fikcyjnego świata” (Jenkins 2007, 260).

${ }^{6}$ Należy zwrócić uwagę, że narracje transmedialne są rozpisane na różne platformy cyfrowe również pod względem treści, natomiast opowieści przepisane (mające rewritingi na innych platformach) należy uznać za transmedialne transfery lub transmedializacje mające cross-platformowe warianty. 
wraz z rozwijaną narracja, wówczas jego specyfika stanie się częścią samej narracji. W takiej sytuacji niemożliwe jest oddzielenie i przeniesienie narracji z jednego medium do drugiego i rozwijanie jej zgodnie ze specyfiką drugiego, ponieważ pewne elementy jednego przenikaja w kontekst innego medium wraz z narracją. W ten sposób tworzą się hybrydy transmedialne, które jednocześnie mogą skutkować doświadczeniem transkulturowym (Załuski 2010, 12).

Transkulturowość doświadczenia transmedialnych narracji jest tym bardziej interesująca z perspektywa ucznia, jeśli w wybranych realizacjach dochodzi do odejścia od kodów symbolicznych na rzecz naturalnych mediów. Tego rodzaju narracją jest zazwyczaj film, który jesteśmy w stanie odczytać bez specjalnego treningu, jest bardziej intuicyjny i charakteryzuje się transkulturowością. Dla ucznia cudzoziemskiego szczególnie istotne mogą okazać się transmedia, w procesie odbioru których to ciało okazuje się źródłem znaczeń: podstawowe doświadczenie intencjonalnego ruchu, wyobrażenia przeszłości i przyszłości, przedjęzykowe metafory konceptualne. Cielesne i afektywne wymiary doświadczania narracji są kluczowe z perspektywy dobrze zaprojektowanej lekcji z uczniem z doświadczeniem migracyjnym. Tym samym wskazujemy uczniowi najbardziej aktualne trendy w rozwoju kultury, w której odbiorca nie tylko czyta, lecz także tworzy teksty kultury. W badaniach nad współczesną kulturą konwergencji Jenkins pisze w tym kontekście o kulturze uczestnictwa, „w której fani i inni konsumenci są zapraszani do aktywnego uczestnictwa w tworzeniu i redystrybucji nowych treści” (Jenkins 2007, 257). Użytkownicy podejmują dialog z mediami, tworząc społeczności, które są aktywnymi odbiorcami i jednocześnie - twórcami kultury. Wydaje się, że teksty kultury uczestnictwa ${ }^{7}$ powinny znaleźć swoje miejsce na zajęciach języka polskiego jako drugiego, ponieważ umożliwiają one każdemu użytkownikowi kultury komentowanie, modyfikowanie i rozpowszechnianie treści w sposób efektywny, a co za tym idzie - naukę języka komunikacyjnego, specjalistycznego i poznawanie kultury polskiej. Dlatego ważnym postulatem wydaje się skonstruowanie listy tekstów kultury, która obejmowałaby

7 Kategoria „teksty kultury uczestnictwa” nawiązuje do dwóch terminów dobrze znanych w polskiej refleksji humanistycznej: kultura uczestnictwa i tekst kultury. Rzecz polega na analizie kultury uczestnictwa z perspektywy jej wytworów - tekstów kultury w szerokim sensie: wszelkiego rodzaju produktów kulturowych o potencjale semiotycznym: literatura, sztuka, film, muzyka, obyczaje, co w efekcie prowadzi do czytania samej kultury (Maryl 2016, 9). W kontekście lekcji języka polskiego zagadnienie to analizowała Anna Dziak, pokazując, jak teksty kultury uczestnictwa można wykorzystać w procesie dydaktycznym (Dziak 2016, 391-410). 
również takie, które umożliwiają uczniowi wykorzystanie transmedialnych i transkulturowych doświadczeń.

Zaprojektowanie lekcji języka polskiego dla uczniów z różnych kręgów kulturowych niewattpliwie należy do zadań ważkich również dlatego, że głównym celem takiej edukacji jest kompetencja międzykulturowa definiowana jako umiejętność współżycia „z ludźmi innymi niż my” (Cushner 2009, 10). Szukanie punktów wspólnych, transkulturowego podłoża doświadczania i poznawania ma wesprzeć nauczycieli i uczniów w skutecznych interakcjach mimo rozbieżnych wzorców myślenia i zachowania. Kompetencja międzykulturowa zakłada, że uczeń jest przygotowany do poradzenia sobie zarówno w globalnej wiosce, jak i heterogenicznych społecznościach lokalnych.

Potrzebne są zatem innowacyjne i skuteczne narzędzia integrujące rozwój kompetencji międzykulturowej z realizacja podstawy programowej z jednoczesnym wykorzystaniem transmedialności współczesnej kultury jako transkulturowego doświadczenia.

\section{Ucząc przez doświadczanie}

\section{Ambient Literature}

Wydaje się, że efekty, o których była mowa powyżej, można osiagnąć podczas zajęć, na których uczniowie pracują z Ambient Literature ${ }^{8}$ Użytkownik/odbiorca/czytelnik ambient literature doświadcza narracji w czasie i w przestrzeni w nieustającym, fizycznym kontakcie ze swoja lokalizacją. Tekst czytany na ekranie, dźwięk dochodzący ze słuchawek i narracja związana z przestrzenia, w której aktualnie się znajdujemy, pozornie nie są zjawiskami nowymi, ale novum jest w tym projekcie potencjał wydarzenia artystycznego/estetycznego będącego doświadczeniem literackim i jednocześnie bezpośrednią szansą przeformułowania doświadczenia codziennego świata. Smartfon i dane w nim gromadzone stają się materiałem, z którego formuje się tekst kultury, a odbiorca staje się częścią immersyjnego doświadczenia zawierającego wszystko to, co wokół niego. Na przykład Breathe (https://breathe-story.com)

\footnotetext{
${ }^{8}$ Jest to dwuletni program badawczy finansowany przez AHRC, a koordynowany przez trzy uniwersytety z Wielkiej Brytanii: UWE Bristol, Bath Spa i Birmingham. W projekcie bada się potencjał doświadczeń artystycznych będących efektem zanurzenia odbiorcy w środowisko elektroniczne.
} 
opowiada o młodej kobiecie, która lubi rozmawiać z duchami, a duchy lubią rozmawiać z nią. Narracja pierwszoosobowa i spersonalizowana książka, w której pojawiaja się nazwy pobliskich ulic i lokali w naszym mieście sprawiaja, że odbiorca inaczej postrzega swój własny pokój. Immersyjne doświadczenie lektury Breathe sprawia, że uczniowie są zaangażowani podczas lektury i nie maja problemu z jej rozumieniem, tym bardziej że czytaja po angielsku. Od wspólnego transmedialnego doświadczenia estetycznego łatwiej przejść do rozmów o romantyzmie europejskim i wreszcie specyficznym polskim, którego najtrudniejszym ogniwem dla ucznia są Driady Adama Mickiewicza. Breathe można wykorzystać do zaprojektowania zajęć dotyczących: pisania opowiadania z punktu widzenia matki i córki, gatunków i rodzajów literackich, omawiając kategorię synkretyzmu istotną w romantyzmie, duchów, lęku i strachu w różnych kulturach.

\section{Poezja eksperymentalna}

Najbardziej oczywistym wykorzystaniem narracji transmedialnych na lekcji języka polskiego jest pisanie fan fiction do lektury szkolnej lub bloga, który jest pamiętnikiem lub dziennikiem bohatera. Dla ucznia cudzoziemskiego rzecz może być za trudna w początkowej fazie nauki z uwagi na zbyt skomplikowany język lektury. Zasadne wydaje się, żeby tradycyjny tekst literacki zastapić poezją eksperymentalna, np. popularną w ostatnim czasie Loesje ${ }^{9}$ tworzoną w różnych językach, która porusza interesujący nas problem w kontekście danej lektury. Loesje może stać się inspiracją do powstania bloga poruszającego konkretny problem ${ }^{10}$ lub raz jeszcze można przenieść ją do sieci i za pośrednictwem generatorów poezji stworzyć własną poezję elektroniczną, która zostanie zinterpretowana na forum klasy i stanie się inspiracją do napisania tekstu argumentacyjnego lub opowiadania. Tym samym

${ }^{9}$ Loesje [luszje] to projekt artystyczny pochodzacy z Holandii (data powstania: 24.11.1983 roku), powstał jako odpowiedź na problemy związane z sytuacją polityczną Holandii w latach 80. XX wieku. Projekt skupia grupę osób działających na całym świecie w celu szerzenia wolności słowa, tolerancji, kreatywności. Dziś Loesje działa w kilkudziesięciu krajach na całym świecie, w Polsce pierwsza publikacja związana z projektem powstała w 2006 roku. Działacze związani z projektem prowadzą szkolenia, międzynarodowe wymiany i warsztaty kreatywnego pisania tekstów, http://www.loesje.pl/index.php?option=com_content\&view=artic le\&id=7\&Itemid=8 [dostęp: 31.01.2019].

10 (MOJA MOWA/ NIE/ PODLEGLA/NIENAWIŚCI http://www.loesje.pl/images/ stories/plakatypdf/2018/Moja_mowa.pdf) 
transmedialne narracje stają się zarówno przedmiotem namysłu ucznia, jak i jego wytworem.

Teatr forum

Teatr forum stanowiący część Teatru Uciśnionych stworzonego przez Augusto Boala jeszcze bardziej angażuje ciało ucznia. W teatrze tym widz jest aktorem i może zmienić bieg historii za sprawą własnej interwencji. Grupa pracująca tą metodą zaczyna inscenizację od wyboru problemu, który chce poruszyć. Uczestnicy pokazują wybrany problem w formie żywego obrazu, zastygając w wymownej pozie. Następnie obraz zostaje rozbudowany do formy etiudy wzbogaconej o ruch, głos i spontaniczny dialog. Z założenia etiuda ta jest kontrowersyjna i prowokacyjna w swojej wymowie, budzi sprzeciw będący warunkiem teatru forum: „Nie ma konfliktu, nie ma forum” (Besnard 2014, 15). Publiczność może w każdej chwili przerwać aktorom, zatrzymać bieg zdarzeń i zaproponować alternatywną wersję wydarzeń, reakcję na problem. Etiuda jest odgrywana przynajmniej trzy razy i uwzględnia wersję widowni, która może włączać się w sytuację sceniczną. Proces odgrywania etiudy i jej przemian moderuje Joker, który zadaje aktorom i widowni pytania.

Etyczny wymiar lekcji języka polskiego

Ambient Literature, poezja eksperymentalna, teatr forum są efektywnymi narzędziami dającymi uczniowi i nauczycielowi dostęp do szerokiej gamy emocji i doświadczeń, ale za pośrednictwem formy, która jest transkulturowa i nieobca osobom z różnych kręgów kulturowych. Uczniowie pracują ciałem i emocjami, ich poznanie jest ucieleśnione, umiejscowione i rozszerzone. Narracja jest poznawana za pomocą symulacji doświadczenia. Kiedy grupa raz „przeżyje” kontakt z duchami dzięki Breathe, być może stworzy fanfiki będące alternatywnym zakończeniem Dz̧iadów. Inscenizacja problemu wykluczenia z powodu pochodzenia może sprawić, że uczniowie zrozumieją postawę Wokulskiego, zanim jeszcze spróbuja zmierzyć się z interpretacją Lalki Bolesława Prusa. W teatrze forum perspektywa innego staje się bowiem fizycznym doświadczeniem. Czytanie tekstów kultury za pomocą tekstów kultury uczestnictwa i tworzenie ich z uczniami daje bezpieczny wgląd w trudne emocje, które razem można wyrazić i przeanalizować. Niewątpli- 
wie bywa to bolesne, ale może doprowadzić do znalezienia nowych dróg wyjścia i zobaczenia konfliktu z nowej perspektywy, autentycznego dialogu $z$ innym.

\section{Wnioski}

Odmienność wciąż budzi lęk i napięcia, co łatwo zauważyć, obserwując codzienne akty dyskryminacji w mediach i w internecie. Trudne, konfliktowe zagadnienia powinny być poruszane w szkole, uczeń powinien się z nimi konfrontować, doświadczać ich za pośrednictwem tekstów kultury uczestnictwa i dyskutować o nich. Tylko w taki sposób stanie się współtwórcą społeczeństwa obywatelskiego. Narracje transmedialne wykorzystywane podczas zajęć są zakotwiczone we wspólnym doświadczeniu uczniów polskich i cudzoziemskich. Wspólne rozważanie konkretnego problemu prowadzi często do sytuacji problemowych, kiedy okazuje się, że u podstaw dyskryminacji, rasizmu, mowy nienawiści leżą różnice kulturowe, etniczne i inne. Dlatego współcześnie kompetencje międzykulturowe są ważniejsze niż kiedykolwiek, ponieważ dzięki nim uczymy się żyć wspólnie ponad podziałami kulturowymi.

Dzieci i młodzież z doświadczeniem migracji trafiający do polskich szkół, ucząc się języka polskiego, rozwijają umiejętności językowe i kulturowe. Istotne jest to, że język polski i kultura polska stają się środkami umożliwiającymi postępowanie procesu integracji i włączania uczniów z doświadczeniem migracji do polskiego systemu edukacyjnego (Gębal 2018, 153). Poza tym dzięki obecności uczniów z doświadczeniem migracji rozwijają się kompetencje językowe i kulturowe dzieci bez takich doświadczeń, a także nauczających. Narracje transmedialne pojawiające się w różnych kontekstach podczas wspólnych spotkań przyjmowanych i przyjmujących, moga ułatwić nawiązywanie kontaktu, wspólne negocjowanie znaczeń, rozbudzanie językowej świadomości, wreszcie - dialog międzykulturowy.

\section{Literatura}

Besnard J.-P., 2014, Theatre forum, Clermont-Ferrand.

Brooks R.A., 1990, Elephants Don't Play Chess, „Robotics and Autonomous Systems”, t. 6. Cushner K., 2009, Human Diversity in Education: An Integrative Approach, New York. 
Dziak A., 2016, Teksty kultury ucz̧estnictwa w szłkole, w: Dąbrówka A., Maryl M., Wójtowicz A., red., Teksty kultury uczestnictwa, Warszawa.

Gębal P., 2018, Podstany dydaktyki jezykea polskiego jako drugiego. Podejście integracyjno-inkluzyjne, Kraków.

Jenkins H., 2007, Kultura konwergencji. Zderzenie starych i nowych mediów, przeł. Bernatowicz M., Filiciak M., Warszawa.

Kaczmarczyk K., 2017, O podstawowych założeniach narratologii transmedialnej i o jej miejscu wśród narratologii klasycznych i postklasycznych, w: Kaczmarczyk K., red., Narratologia transmedialna. Teorie, praktyki, wyzwania, Kraków.

Lakoff G., Johnson M., 1980, Metaphors We Live By, Chicago.

Lakoff G., Johnson M., 1999, Philosophy in the Flesh: The Embodied Mind and Its Challenge to Western Thought, New York.

Lipińska E., Seretny A., 2018, Od jezyka pierwszego przez odziedziczony i drugi do jezylka ojczystego o polsz̨ryzźnie polskiego ucznia imigranta/reemigranta, w: Gębal P., red., Edukacja wobec migracji. Konteksty glottodydaktyczne i pedagogiczne, Kraków.

Maryl M., 2016, Teksty - kultury - uczestnictwa, w: Dąbrówka A., Maryl M., Wójtowicz A., red., Teksty kultury uczestnictwa, Warszawa.

Menary R., 2010, Introduction to the Special Issue on 4E Cognition, „Phenomenology and the Cognitive Sciences", t. 9, nr 4.

Moryń M., 2008, Patos życia a doświadczenie w „Nowej fenomenologii” Hermanna Schmitza, „Słupskie Studia Filozoficzne", nr 7.

Pamuła-Behrens A., Szymańska M., 2018b, Nauczanie jezyka edukacji szkolnej uczniów z doświadcz̧eniem migracji, „Języki Obce w Szkole”, nr 2.

Ryan M.-L., 2015, Transmedia Storytelling. Industry Buzzword or New Narrative Experience?, „Storyworlds: A Journal of Narrative Studie”, nr 2 (7).

Welsch W., 1998, Transkulturowosc. Nowa koncepija kultury, w: Kubicki R., red., Filozoficzne konteksty koncepcji rozumu transwersalnego. Wokót koncepcji Wolfganga Welscha, Poznań.

Wilkoszewska K., 2004, Estetyka transkulturowa, Kraków.

Wilkoszewska K., 2010, O moz̨liwosci dzielenia doswiadczeń. Perspektywa transkulturowa, „Annales Universitias Mariae Curie-Skłodowska", vol. XXXV.

Załuski T., 2010, Transmedialność?, w: Załuski T., red., Sẓtuki w præestrzeni transmedialnej, Lódź.

\section{Netografia}

Duch W., 2007, Neuroestetyka i ewolucyjne podstawy przezjyc estetycznych, http://www.fizyka.umk. $\mathrm{pl} /$ publications/kmk/07-Neuroestetyka.pdf [dostęp: 20.06.2018].

Pamuła-Behrens A., Szymańska M., 2018a, Metodyka nauczania jezyka edukacji szkolnej uczniów z doświadczeniem migracji. Metoda JES-PL - MATEMATYKA, Kraków, http://fundacjareja. eu/do-pobrania/ [dostęp: 30.03.2019].

https://breathe-story.com [dostęp: 30.03.2019].

http://www.loesje.pl/images/stories/plakatypdf/2018/Moja_mowa.pdf [dostęp: 30.03.2019]. 